Article

\title{
Evaluation of Five Satellite Top-of-Atmosphere Albedo Products over Land
}

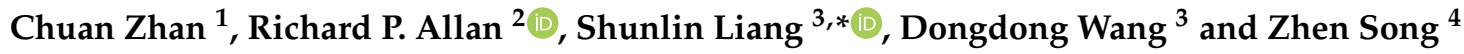 \\ 1 State Key Laboratory of Remote Sensing Science, Faculty of Geographical Science, Beijing Normal University, \\ Beijing 100875, China; zhanchuan@mail.bnu.edu.cn \\ 2 Department of Meteorology and National Centre for Earth Observation, University of Reading, \\ Reading RG6 6BB, UK; r.p.allan@reading.ac.uk \\ 3 Department of Geographical Sciences, University of Maryland, College Park, MD 20742, USA; \\ ddwang@umd.edu \\ 4 Department of Geosciences, Texas Tech University, Lubbock, TX 79409, USA; zhen.song@ttu.edu \\ * Correspondence: sliang@umd.edu; Tel.: +1-301-405-4556
}

Received: 20 October 2019; Accepted: 4 December 2019; Published: 6 December 2019

check for updates

\begin{abstract}
Five satellite top-of-atmosphere (TOA) albedo products over land were evaluated in this study including global products from the Advanced Very High Resolution Radiometer (AVHRR) (TAL-AVHRR), Moderate Resolution Imaging Spectroradiometer (MODIS) (TAL-MODIS), and Clouds and the Earth's Radiant Energy System (CERES); one regional product from the Climate Monitoring Satellite Application Facility (CM SAF); and one harmonized product termed Diagnosing Earth's Energy Pathways in the Climate system (DEEP-C). Results showed that overall, there is good consistency among these five products, particularly after the year 2000. The differences among these products in the high-latitude regions were relatively larger. The percentage differences among TAL-AVHRR, TAL-MODIS, and CERES were generally less than 20\%, while the differences between TAL-AVHRR and DEEP-C before 2000 were much larger. Except for the obvious decrease in the differences after 2000, the differences did not show significant changes over time, but varied among different regions. The differences between TAL-AVHRR and the other products were relatively large in the high-latitude regions of North America, Asia, and the Maritime Continent, while the differences between DEEP-C and CM SAF in Europe and Africa were smaller. Interannual variability was consistent between products after 2000, before which the differences among the three products were much larger.
\end{abstract}

Keywords: TOA albedo; evaluation; TAL-AVHRR; TAL-MODIS; CERES; CM SAF; DEEP-C

\section{Introduction}

Top-of-atmosphere (TOA) albedo is a crucial component of the energy budget of the Earth [1,2]. Estimation of TOA albedo from remote sensing data is a unique means to generate TOA albedo products at regional or global scales. Different algorithms have been proposed to estimate TOA albedo from satellite data, and multiple TOA albedo products from both broadband and narrowband sensors have been developed [3-17], some of which have a relatively high spatial resolution that is helpful in studying the energy budget at regional scales [15-17].

Currently, different researchers have used these products to analyze the Earth's energy budget. For instance, numerous studies have attempted to calculate the Arctic energy budget based on the energy equation integrated over the atmospheric column using different reanalysis datasets [18-23]. TOA products based on satellite data were used to calculate the downward net radiative flux at the TOA because of their better accuracy than reanalysis datasets. In addition, several studies have used 
the Diagnosing Earth's Energy Pathways in the Climate system (DEEP-C) products to calculate the surface energy budget [24-26]. Smith et al. [24] built upon the DEEP-C datasets by including estimates of the ocean heat content trends and developing a combined simulated/observation-based record of net downward TOA radiation extending back to 1960. Trenberth and Fasullo [25] stated that the net flux of energy into the surface can be estimated when the net downward radiation at the TOA (which can be obtained from DEEP-C) is combined with atmospheric energy transport and its divergence. By employing net radiation at the TOA from DEEP-C, Mayer et al. [26] further refined estimates of the net surface energy flux based on this method.

To ensure these products are more effectively used, it is necessary to evaluate them. Unlike ground-based parameters, the TOA albedo products cannot be validated by direct comparison to in situ measurements. The quality of different data records can only be evaluated by intercomparison to other products [27]. In addition to the widely used Clouds and the Earth's Radiant Energy System (CERES) product, there are multiple TOA albedo satellite products available from different satellite observations using different estimation algorithms. For instance, Wang and Liang [15] have developed TOA albedo products over land based on Moderate Resolution Imaging Spectroradiometer (MODIS) data (TAL-MODIS) and compared them to CERES data. Urbain et al. [16] released the Climate Monitoring Satellite Application Facility (CM SAF) TOA radiation MVIRI/SEVIRI data record and made intercomparisons to the CERES data. Song et al. [17] developed a long-term record of TOA albedo over land from Advanced Very High Resolution Radiometer (AVHRR) data (TAL-AVHRR) and compared it to both CM SAF and CERES data. However, no study has systematically compared all five products. In this study, the five TOA albedo products were comprehensively intercompared to demonstrate their differences.

The organization of this paper is as follows. Section 2 introduces the CERES, TAL-AVHRR, TAL-MODIS, CM SAF, and DEEP-C TOA albedo products. Data processing methods are also described in this section. The results of the differences between the five products and the corresponding analysis are presented in Section 3. Discussion is given in Section 4. Conclusions are drawn in the final section.

\section{Data and Methods}

Figure 1 shows the time span of the five TOA albedo products assessed in this study. Each dataset is briefly described in the following section.

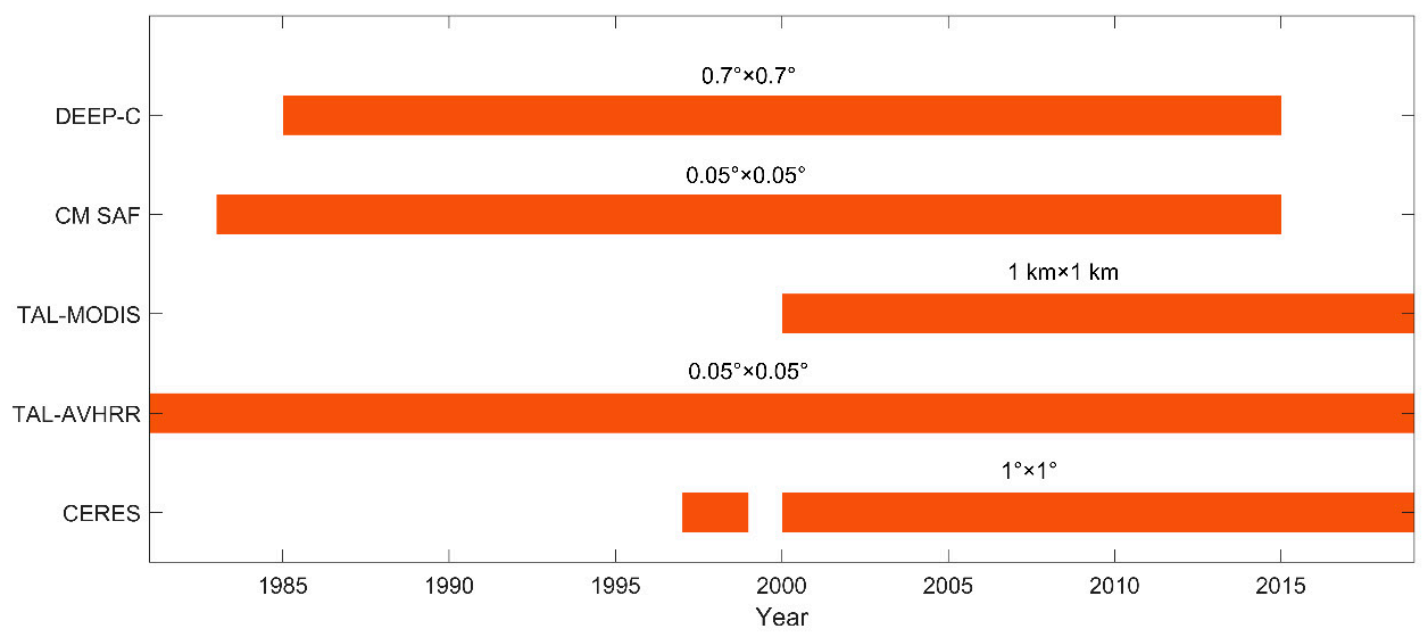

Figure 1. Time span of the five TOA albedo products evaluated in this study.

\subsection{Clouds and the Earth's Radiant Energy System (CERES)}

CERES, a broadband instrument on board Terra, Aqua, and Suomi NPP, measures shortwave reflected radiation $(0.3-5 \mu \mathrm{m})$, longwave thermal radiation $(8-12 \mu \mathrm{m})$, and all wavelengths of radiation 
$(0.3-200 \mu \mathrm{m})$ [28]. The spatial resolution of CERES on Terra and Aqua is nearly $20 \mathrm{~km}$ at the nadir. Based on the observed shortwave radiance, the CERES shortwave fluxes have been developed using an angular distribution model (ADM) [10]. Moreover, the Level-2 Single Scanner Footprint (SSF) that provides instantaneous TOA albedo at a resolution of $20 \mathrm{~km}$ and the Level-3 Synoptic products (SYN1deg) that provide hourly, 3-hourly, daily, and monthly mean TOA radiative fluxes have also been developed [29]. In this study, the SYN1deg data, which began in March 2000 at a resolution of 1 degree, were used in the intercomparison.

\subsection{TOA Albedo from AVHRR Data (TAL-AVHRR)}

Recently, Song et al. [17] released a long-term record of TOA albedo over land generated from AVHRR data, which provides the longest continuous record of global satellite observations since 1981. Direct estimation models were built to derive instantaneous TOA broadband albedo. Cloudy-sky, clear-sky, and snow-cover conditions were separately considered, and the training data for building the model were from real AVHRR observations and high-resolution TOA albedo datasets retrieved from MODIS data [15]. The instantaneous albedo values were converted to daily and monthly mean values based on the diurnal curves from the CERES 3-hourly flux dataset. The dataset has covered global land at a spatial resolution of 0.05 degree since 1981. Notably, the product has some gaps in 1994 and 2000 because of the unavailability of the source AVHRR data. It is the first long-term high spatial resolution TOA albedo product with global coverage over land.

\subsection{TOA Albedo from MODIS Data (TAL-MODIS)}

Wang and Liang [15] retrieved TOA albedo over land from multispectral data collected by MODIS using a hybrid method that is based on extensive atmospheric radiative transfer simulations considering various surface and atmospheric conditions. Different algorithms have been developed for clear-sky and cloudy-sky conditions, respectively. For the clear-sky condition, the Polarization and Directionality of the Earth's Reflectances/Polarization and Anisotropy of Reflectances for Atmospheric Sciences coupled with observations from a Lidar (POLDER-3/PARASOL) bidirectional reflectance distribution function database has been used to consider surface reflectance anisotropy, thus generating TOA spectral and then broadband albedo. For the cloudy-sky condition, the surface is assumed to be Lambertian and the TOA broadband albedo is directly obtained. Similar to TAL-AVHRR, after generating the instantaneous TAL-MODIS, the daily/monthly mean TOA albedo is needed for further application. Instead of using the CERES 3-hourly flux dataset when generating daily TAL-AVHRR, the diurnal curves from the CERES hourly dataset were used to generate daily TAL-MODIS to improve the accuracy. The dataset has covered global land at a spatial resolution of $1 \mathrm{~km}$ since 2000. In this study, we aggregated it into a resolution of $0.05^{\circ}$ for better intercomparison to other TOA albedo products.

\subsection{Climate Monitoring Satellite Application Facility (CM SAF)}

The CM SAF TOA Radiation Meteosat Visible and InfraRed Imager/Spinning Enhanced Visible and InfraRed Imager (MVIRI/SEVIRI) Data Record provides the TOA reflected solar and emitted thermal radiation under all sky conditions. The dataset covers a 32-year-time period from 1 February 1983 to 30 April 2015. The long data record is helpful in analyzing the changes in the Earth's energy budget during the past several decades. Narrowband to broadband regressions have been derived based on the overlap between the MVIRI and Geostationary Earth Radiation Budget instruments from 2004 to 2006, and the CERES Tropical Rainfall Measurement Mission (TRMM) ADMs have been used to compute the TOA reflected solar radiation from the broadband radiances [16]. The products include daily means, monthly means, and monthly averages of the hourly integrated values. The data covers the region $70^{\circ} \mathrm{N}-70^{\circ} \mathrm{S}$ and $70^{\circ} \mathrm{W}-70^{\circ} \mathrm{E}$ at a spatial resolution of $0.05^{\circ}$. It has the same resolution as that of TAL-AVHRR and its long-term series coverage also contributes to the intercomparison. 


\subsection{Diagnosing Earth's Energy Pathways in the Climate System (DEEP-C)}

The DEEP-C project reconstructed TOA radiative energy fluxes (outgoing longwave radiation (OLR), absorbed shortwave radiation (ASR), and net radiation) combining satellite data, atmospheric reanalysis (ERA-Interim), and climatic model (AMIP5) simulations [30]. The TOA datasets cover the globe at a spatial resolution of approximately $0.7^{\circ}$ from 1985 to 2015 . CERES EBAF v2.8 data were used from March 2000 to May 2015. Therefore, a comparison with CERES over this period will only highlight differences in the EBAF version and spatial interpolation. From January 1985 to February 2000 , the monthly mean radiative fluxes were reconstructed using monthly seasonal cycles from 2001-2005 CERES data, spatial distribution of radiative fluxes represented by ERAI data constrained by hemispheric mean changes in radiative fluxes from the Earth Radiation Budget Satellite (ERBS) wide field of view (WFOV) measurements. Note that DEEP-C only provides the ASR, which is calculated as the difference between incoming solar radiation from the Solar Radiation and Climate Experiment and CERES outgoing shortwave radiative flux, instead of the TOA albedo. Therefore, we calculated the TOA albedo with the TOA incoming solar flux from the CERES data.

\subsection{Data Processing}

As the five TOA albedo products were of different spatial resolutions, we compared them at three different spatial resolutions. TAL-AVHRR, TAL-MODIS, and CM SAF TOA albedo products at a $0.05^{\circ}$ resolution were first compared, and then aggregated to $0.7^{\circ}$ for comparison with DEEP-C, and finally were all aggregated to $1^{\circ}$ to compare to the CERES TOA albedo product. The aggregation was weighted by the grid areas, which varied with latitude.

For CM SAF, the calculation is straightforward as it includes both the shortwave upward fluxes and the shortwave downward fluxes. For DEEP-C, however, as it only contains the TOA ASR, we needed to use the shortwave downward fluxes from other datasets. Considering that the CERES data are of relatively high accuracy and the TOA incoming solar flux is relatively constant, we calculated the mean value of the CERES TOA incoming solar flux for each month from 2001 to 2016. By subtracting the ASR from DEEP-C, the shortwave upward fluxes at TOA were obtained. Finally, the TOA albedo of the DEEP-C dataset was calculated.

The intercomparison was performed at different spatial extents including global, latitudinal, and regional scales. The latitudinal average was calculated for each $30^{\circ}$ latitudinal band, and the regional average was calculated based on different regions. The comparison was also performed during different seasons: December-January-February (DJF), March-April-May (MAM), June-July-August (JJA), and September-October-November (SON), where the December value is from the previous year. Notably, TAL-AVHRR and TAL-MODIS include only land, while the other three products include both land and ocean. Therefore, before the intercomparison, we extracted the land from the other three products using a global land mask.

\section{Results Analysis}

Figure 2 shows the average TOA albedo of CERES from 2001 to 2017 in January and July, respectively. From Figure 2, one can see that Greenland and Antarctica stand out because of the high TOA albedo value due to the ice/snow cover, and the values in the northern hemisphere winter were also relatively larger. Next, five TOA albedo products were intercompared at three different spatial resolutions $\left(0.05^{\circ}, 0.7^{\circ}\right.$, and $\left.1^{\circ}\right)$, respectively. Considering that percentage differences, which are obtained from dividing the difference of two products by their average, are more meaningful than absolute differences, all the difference maps shown in this study (Figures 3-6) are presented and discussed in percentage differences. 

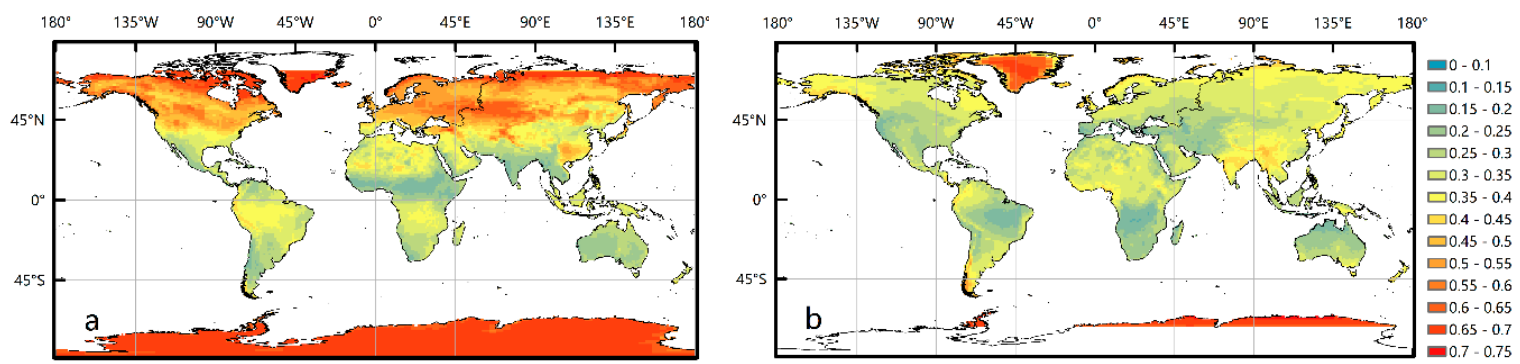

Figure 2. The average TOA albedo of CERES from 2001 to 2017 in (a) January; (b) July.

\subsection{Intercomparisons at $0.05^{\circ}$ Spatial Resolution}

To determine the exact differences in distribution between CMSAF and TAL-AVHRR, we calculated the differences in the mean value of the TOA albedo from 1984 to 2014 using CM_SAF minus TAL-AVHRR with 1994 and 2000 excluded because TAL-AVHRR had some gaps due to the unavailability of the source AVHRR data in these two years. Figure 3a shows that the percentage differences were mostly less than $20 \%$, but much larger around $50^{\circ} \mathrm{N}, 50^{\circ} \mathrm{E}$ in January. As for July, most of the differences were positive, indicating that overall CM SAF was larger than TAL-AVHRR in July. Figure 4 shows the differences in the mean value of the TOA albedo from 2001 to 2014 using TAL-MODIS minus TAL-AVHRR. From this figure, one can see that in January, the TOA albedo was lower in AVHRR than MODIS in most regions in the northern hemisphere while in July, the differences were quite large around $70^{\circ} \mathrm{N}$.
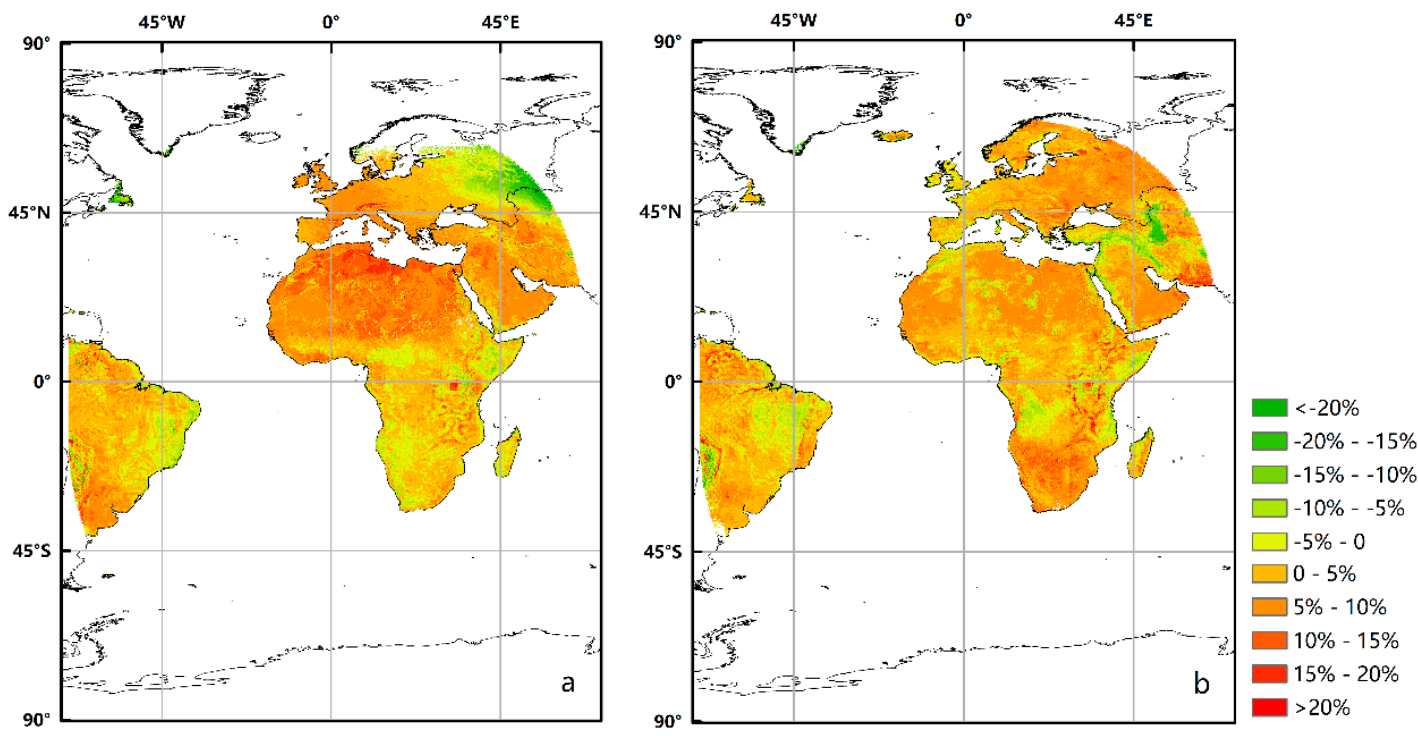

Figure 3. Percentage differences in the mean value of the TOA albedo from 1984 to 2014 between CM SAF and TAL-AVHRR, excluding 1994 and 2000 in (a) January; (b) July. 


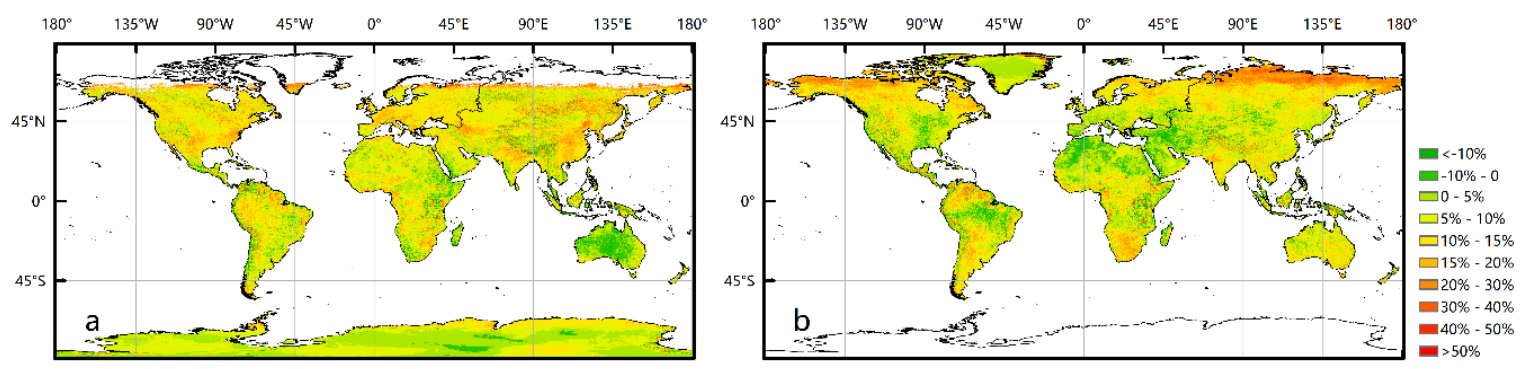

Figure 4. Percentage differences in the mean value of the TOA albedo from 2001 to 2014 between TAL-MODIS and TAL-AVHRR in (a) January; (b) July.

\subsection{Intercomparisons at a $0.7^{\circ}$ Spatial Resolution}

Four TOA albedo products (TAL-AVHRR, TAL-MODIS, DEEP-C, and CM SAF) were intercompared at a $0.7^{\circ}$ spatial resolution. Considering that DEEP-C products are generated using different source data before and after 2000, we chose the year 1986 and 2006 for intercomparison. Additionally, as the spatial resolution of $0.7^{\circ}$ and $1^{\circ}$ are quite close, here we chose the area of $70^{\circ} \mathrm{N}-70^{\circ} \mathrm{S}$ and $70^{\circ} \mathrm{W}-70^{\circ} \mathrm{E}$ to show more detailed information. The results are shown in Figure 5. Overall, the percentage differences between the four products were less than $20 \%$. The differences between TAL-AVHRR and DEEP-C were relatively smaller than the differences between CM SAF and DEEP-C. In addition, the differences between these products become smaller after 2000.
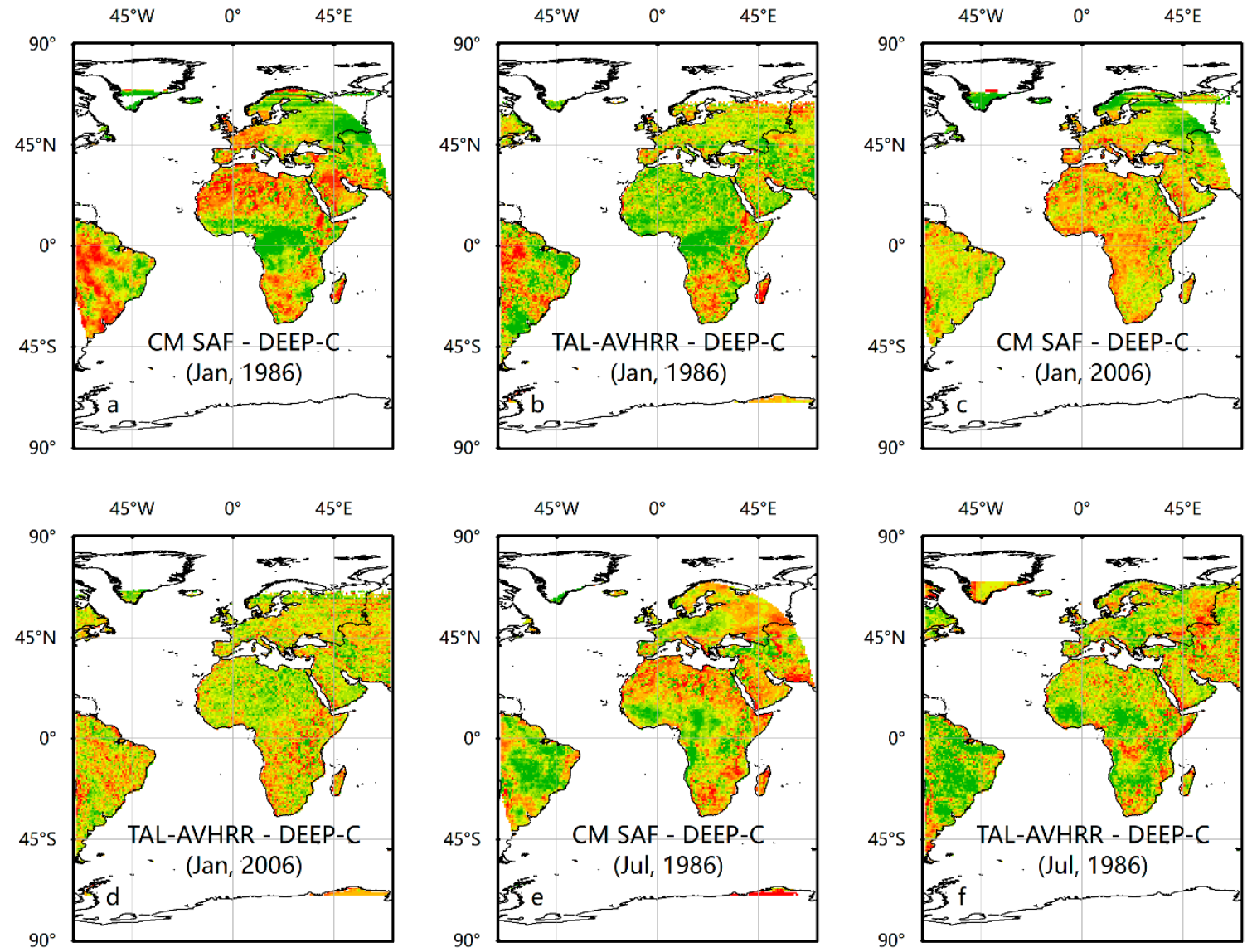

Figure 5. Cont. 

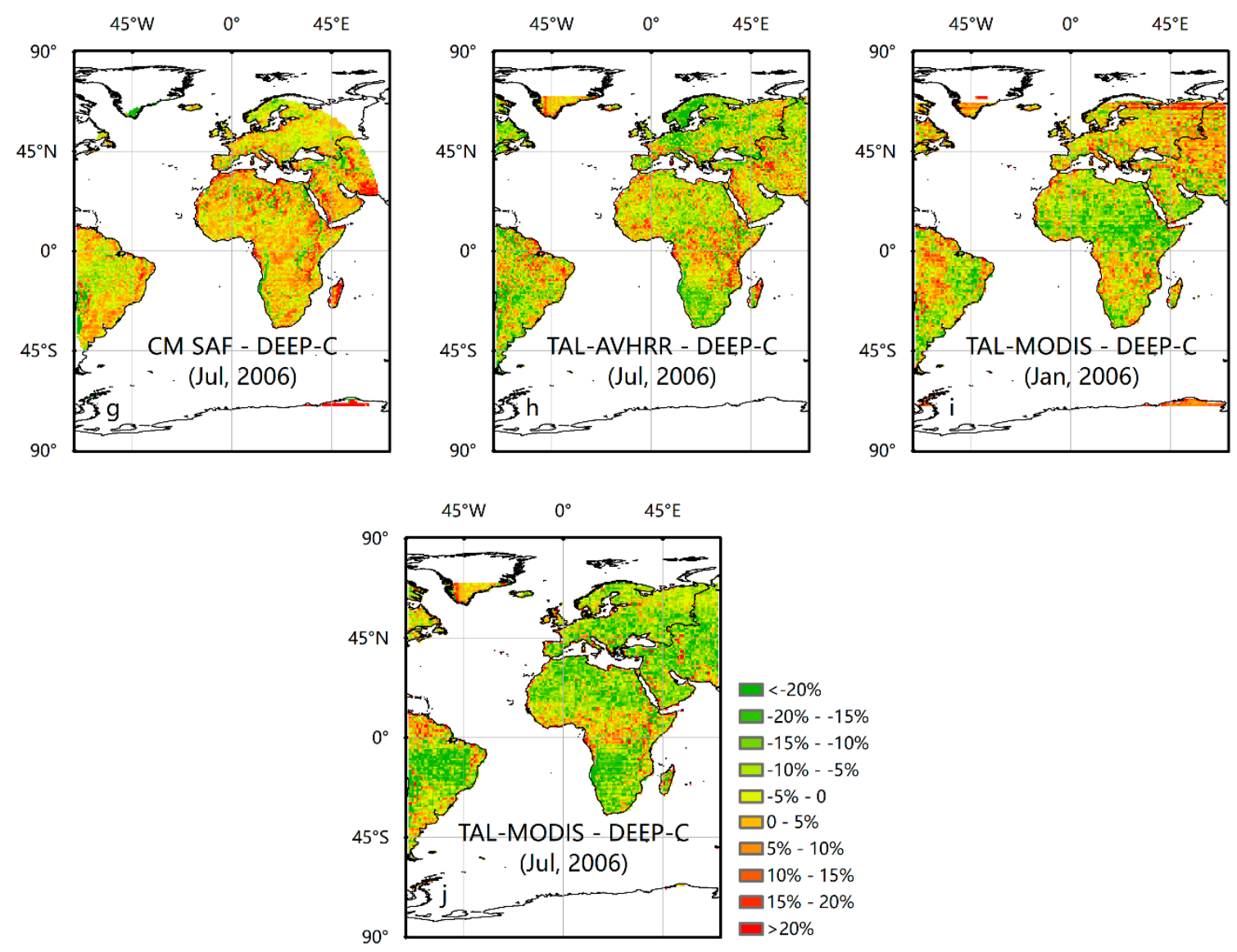

Figure 5. Percentage differences between (a) CM SAF and DEEP-C in January, 1986; (b) TAL-AVHRR and DEEP-C in January, 1986; (c) CM SAF and DEEP-C in January, 2006; (d) TAL-AVHRR and DEEP-C in January, 2006; (i) TAL-MODIS and DEEP-C in January, 2006; $(\mathbf{e}-\mathbf{h}, \mathbf{j})$ are the same but for July.

\subsection{Intercomparisons at a $1^{\circ}$ Spatial Resolution}

All five TOA albedo products, aggregated into a $1^{\circ} \times 1^{\circ}$ spatial resolution, were intercompared, and the global and regional differences between these products are presented here.

\subsubsection{Global Differences}

Figure $6 \mathrm{a}, \mathrm{b}$ show differences in the mean value of the TOA albedo in January 2006 between CERES and TAL-AVHRR, and the differences between TAL-MODIS and TAL-AVHRR, respectively. Overall, the differences between CERES and TAL-AVHRR in January were the smallest out of the four. The distribution of the differences between TAL-MODIS and TAL-AVHRR in January was quite irregular. In July, the pattern of Figure $6 c$,d was similar, and there were obvious differences in the high-latitude area, except for Greenland. However, most of the percentage differences were less than $20 \%$.

It is not sufficient to conduct intercomparisons only at a global scale over land because these products may perform differently among different regions. To comprehensively compare these products, the regional differences need to be calculated and analyzed. 


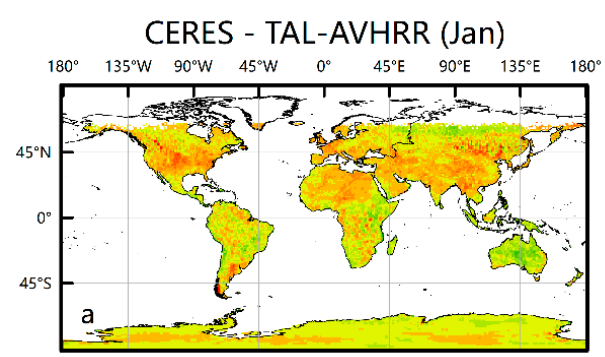

CERES - TAL-AVHRR (Jul)

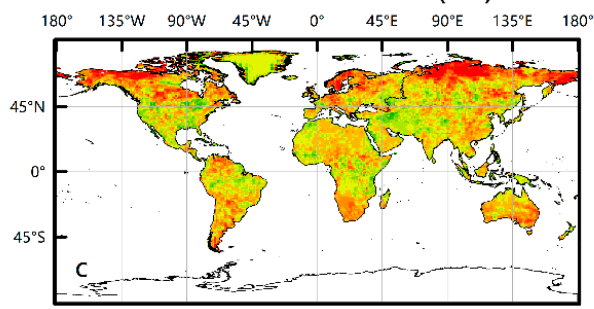

TAL-MODIS - TAL-AVHRR (Jan)

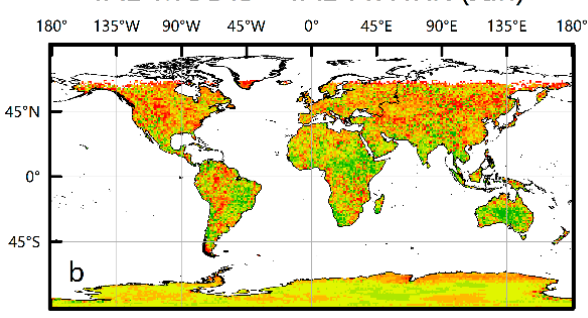

TAL-MODIS - TAL-AVHRR (Jul)

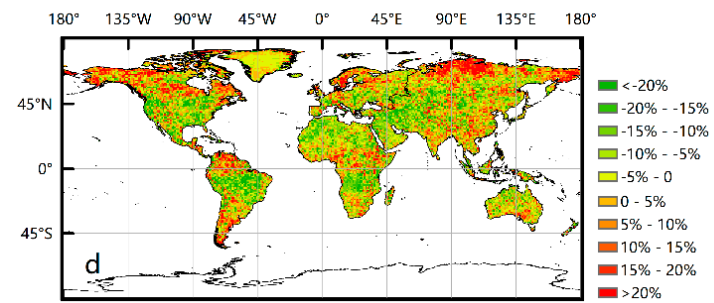

Figure 6. Percentage differences between (a) CERES and TAL-AVHRR; (b) TAL-MODIS and TAL-AVHRR in January 2006, (c,d) are the same but for July.

\subsubsection{Regional Differences}

As Figure 7 shows, the black, green, blue, and red lines stand for the TAL-AVHRR, TAL-MODIS, DEEP-C, and CERES monthly mean TOA albedo anomalies of different latitudinal bands, respectively. CM SAF was excluded in this part due to the limited spatial coverage. Before 2000, the differences between TAL-AVHRR and DEEP-C were much larger, and DEEP-C showed a more stable trend than that of TAL-AVHRR. Notably, there was an obvious peak value during 1992 in the Northern Hemisphere caused by the eruption of Mount Pinatubo in the Philippines in 1991. After 2000, when the CERES data and TAL-MODIS were included in the intercomparison, one can see that overall, DEEP-C matched very well with the CERES data. This is not surprising because CERES data were used after 2000 to develop the DEEP-C datasets. In addition, overall, TAL-MODIS matched well with the DEEP-C and CERES data. As AVHRR becomes much more stable after 2000, TAL-AVHRR matched much better with DEEP-C during this period. The largest difference between TAL-AVHRR and DEEP-C decreased from 0.05 before 2000 to 0.007 after.

To fully understand how different TOA albedo products perform in different regions, we divided the world area into ten parts, as shown in Figure S1 [31,32]. The division overall matched that of Rao's work [31], except for some small changes in the boundary of Europe and Asia. Specifically, the boundary of Europe was set as $70^{\circ} \mathrm{N}$ instead of $80^{\circ} \mathrm{N}$ because of the limit of the coverage of CM SAF. The boundary of Asia1 was set as $60^{\circ} \mathrm{E}$ instead of $45^{\circ} \mathrm{E}$ to avoid overlap with the coverage of Europe. We made comprehensive intercomparisons among the five products by analyzing their performance in these ten regions, respectively.

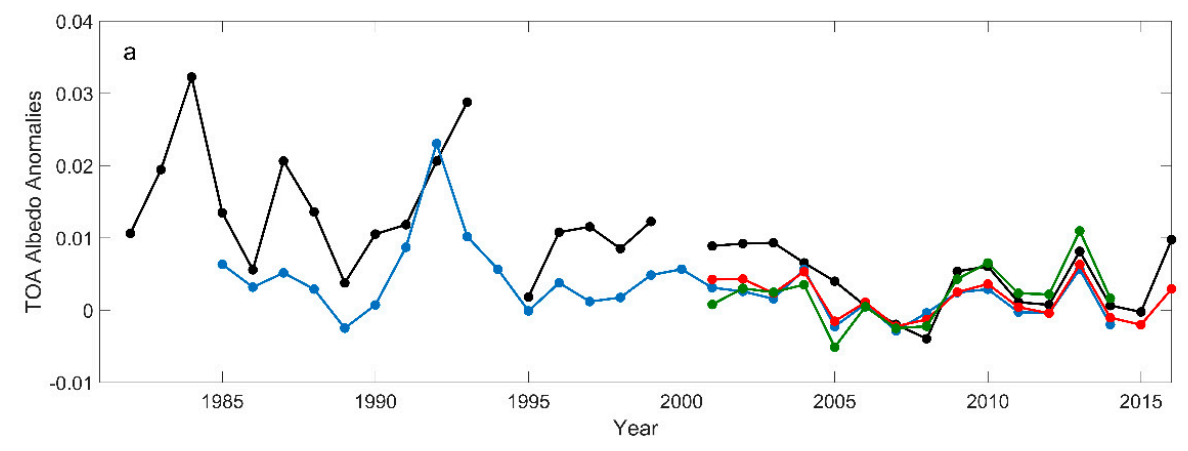

Figure 7. Cont. 

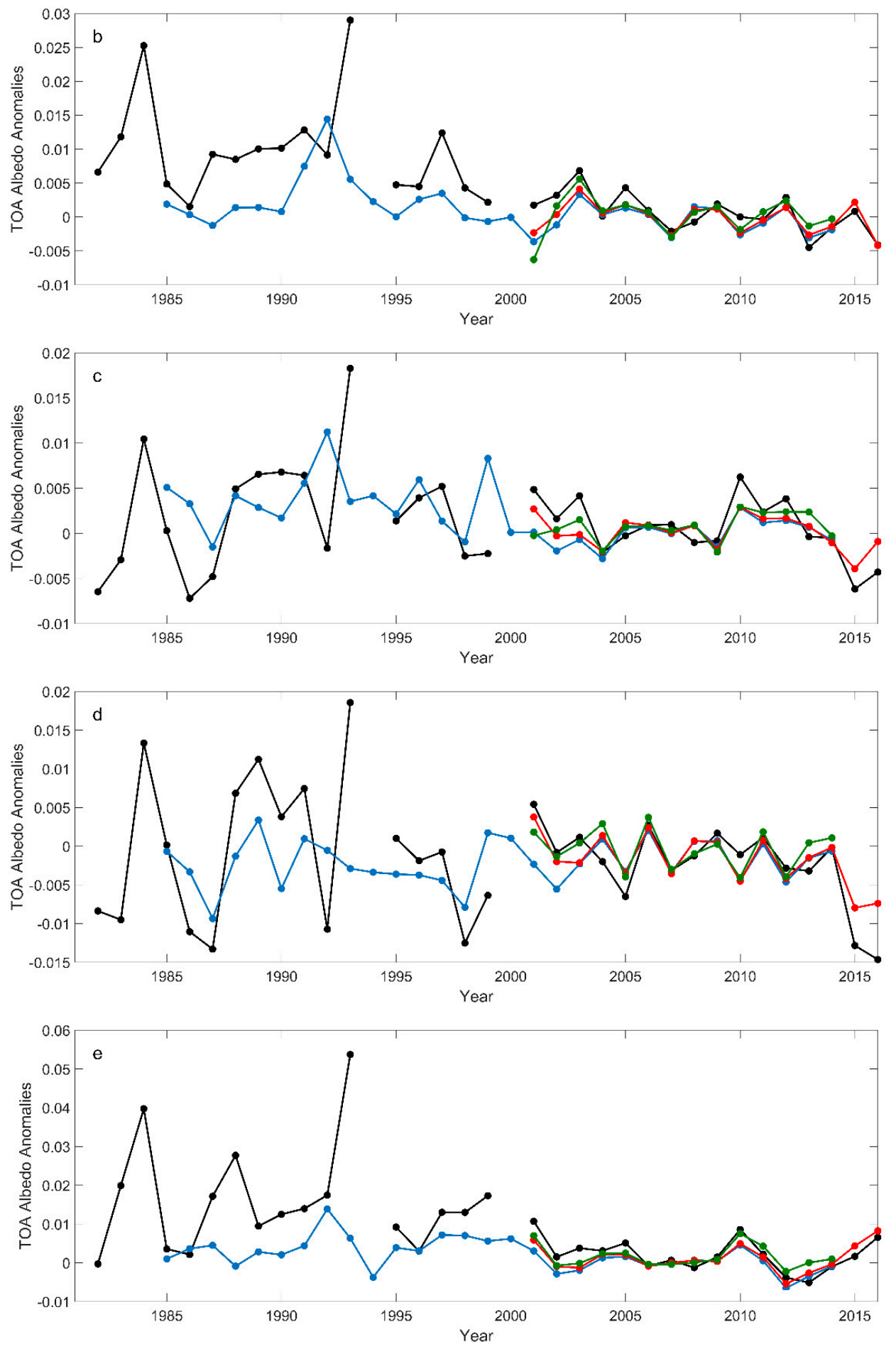

Figure 7. Cont. 


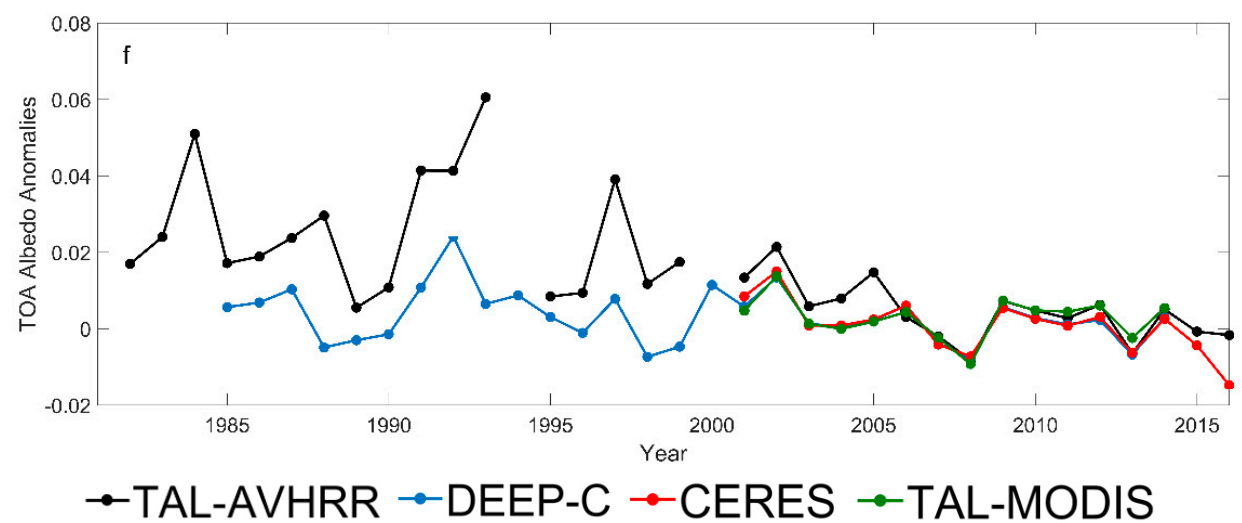

Figure 7. TAL-AVHRR, TAL-MODIS, DEEP-C, and CERES monthly mean TOA albedo anomalies of different latitudinal bands with a common base period $2006-2009$. (a) $60^{\circ}-90^{\circ} \mathrm{N}$; (b) $30^{\circ}-60^{\circ} \mathrm{N}$; (c) $0-30^{\circ} \mathrm{N}$; (d) $0-30^{\circ} \mathrm{S}$; (e) $30^{\circ}-60^{\circ} \mathrm{S}$; (f) $60^{\circ}-90^{\circ} \mathrm{S}$.

The monthly mean TOA albedo anomalies of Africa and Europe are shown in Figure 8. The results were deseasonalized by subtracting the average values of each season when calculating the anomalies. Five products were compared in this region, and Figure S2 shows the results of other regions. From these figures, one can see that the differences among TAL-AVHRR, DEEP-C, and CM SAF were much larger before 2000, particularly the differences between TAL-AVHRR and the other two products. Specifically, the differences between the anomalies of TAL-AVHRR and DEEP-C could be close to 0.08 during some years before 2000. The differences between DEEP-C and CM SAF in Europe and Africa, however, were much smaller.
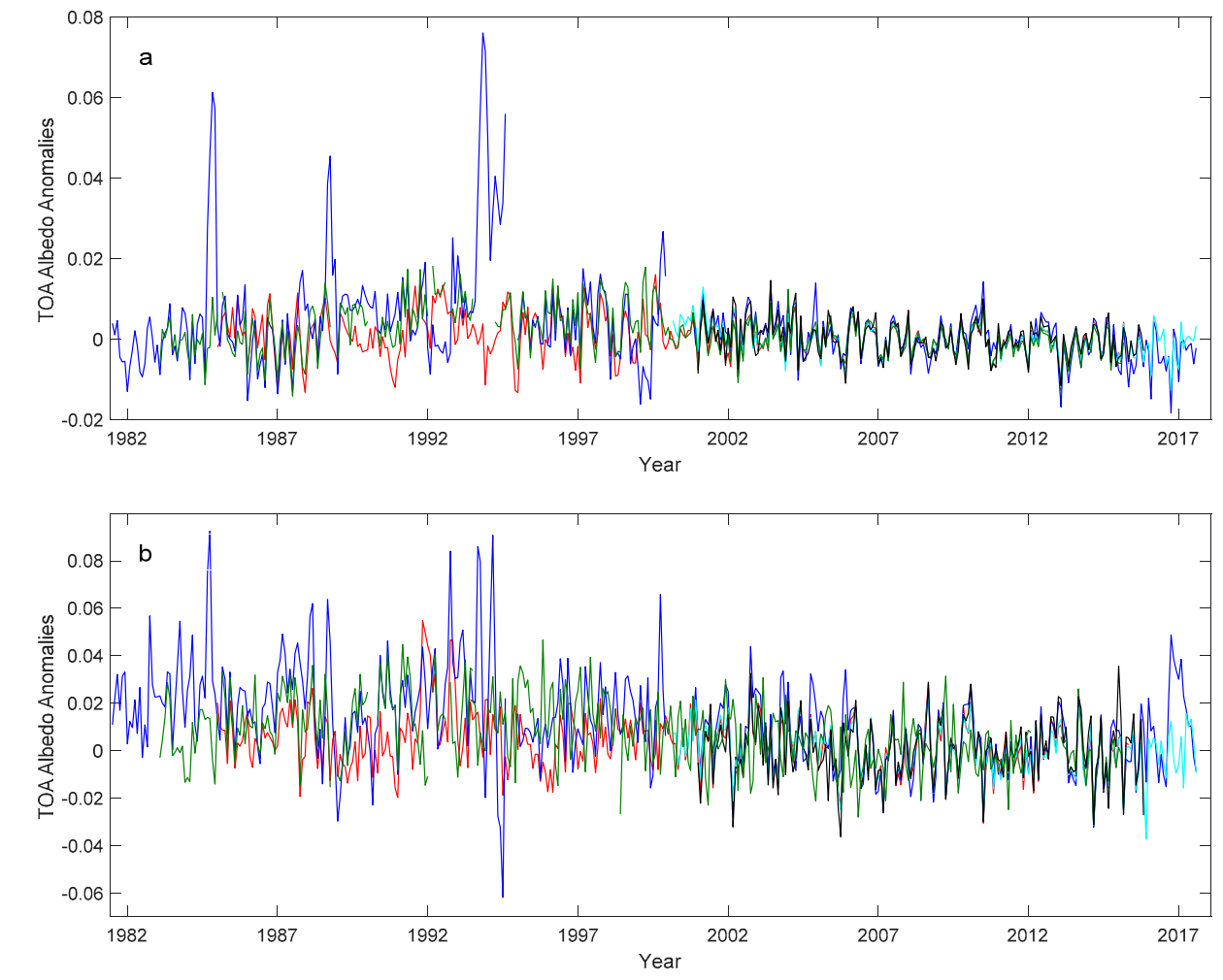

- DEEP-C - TAL-AVHRR - CERES - CM SAF - TAL-MODIS

Figure 8. DEEP-C, TAL-AVHRR, TAL-MODIS, CERES, and CM SAF monthly mean TOA albedo deseasonalized anomalies in (a) AFR and (b) EUR with a common base period 2006-2009. 
As some overestimations and underestimations in these datasets are seasonally dependent and can be removed following the deseasonalizing process [17], some differences may not be shown in this figure. Therefore, we also calculated the absolute value of the DEEP-C, TAL-AVHRR, TAL-MODIS, CERES, and CM SAF monthly mean TOA albedo for different regions. Figure 9 indicates the results of the Maritime Continent (MCT). The results of the other regions are shown in Figure S3.

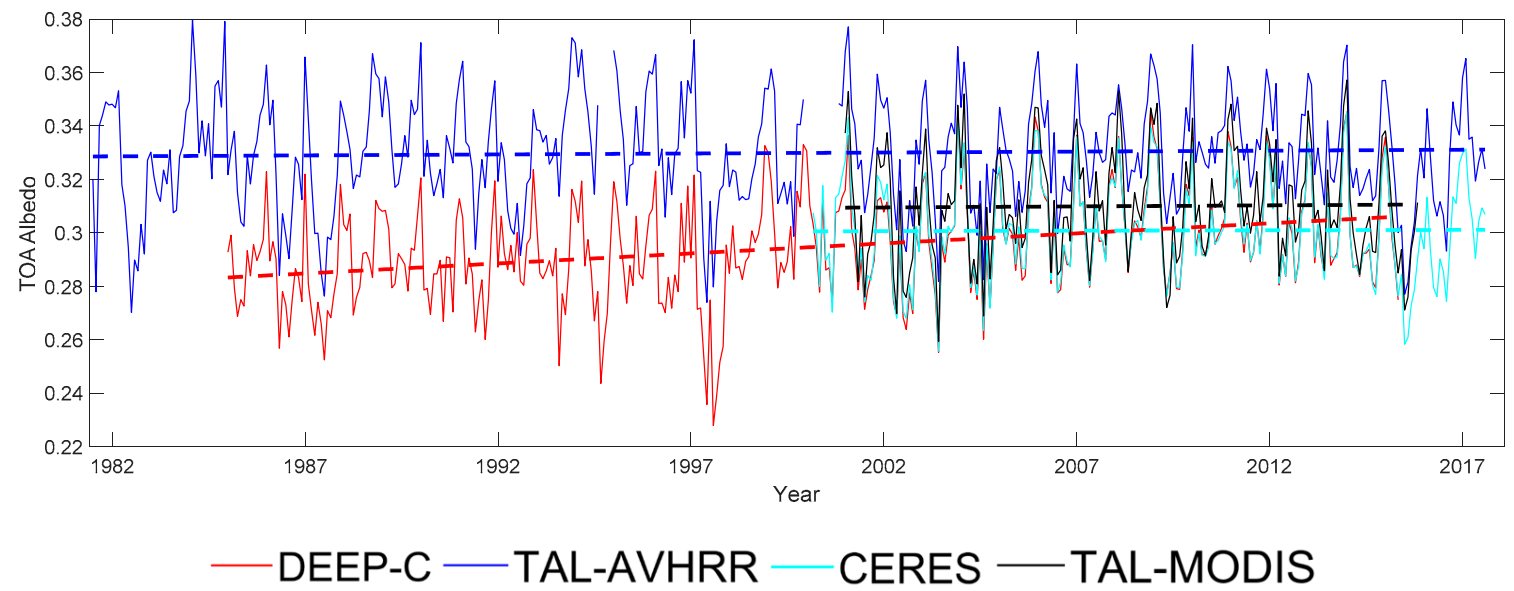

Figure 9. Absolute value of DEEP-C, TAL-AVHRR, TAL-MODIS, and CERES monthly mean TOA albedo in MCT. Trendlines are shown as dashed lines.

After calculating the corresponding absolute values, we found that there were obvious overestimations in TAL-AVHRR, and that they were larger during the years before 2000, as shown in Figure 9. This figure corresponds to the region of MCT, corresponding to the area of Indonesia, a country consisting of more than 17,000 islands. Considering that TAL-AVHRR only generates TOA albedo over land, islands may easily lead to overestimations as mixed pixels always occur in islands, particularly those that are small.

The root mean square differences (RMSD) and mean differences (MD) between different products during different periods are summarized in Tables 1 and 2. The maximum RMSD and MD were 0.031 and 0.011, respectively, corresponding to the difference between TAL-AVHRR and DEEP-C during autumn in the region $90^{\circ} \mathrm{N}-90^{\circ} \mathrm{S}$ and $70^{\circ} \mathrm{E}-180^{\circ} \mathrm{E}$. The RMSDs were smaller when comparing the difference between TAL-AVHRR and CERES with the difference between TAL-AVHRR and DEEP-C. By comparing Table 1 to Table 2, one can see that the RMSDs of CM SAF did not change much, while the RMSDs of TAL-AVHRR during all seasons became much smaller after 2000 and TAL-MODIS performed relatively well. In addition, as most of the MDs of TAL-AVHRR were positive values, one can conclude that there were more overestimations of TAL-AVHRR than underestimations among the different regions. In the regions $70^{\circ} \mathrm{N}-70^{\circ} \mathrm{S}$ and $70^{\circ} \mathrm{W}-70^{\circ} \mathrm{E}$, the MD of TAL-AVHRR decreased because this region does not contain high-latitude areas, also indicating that TAL-AVHRR does not perform well in high-latitude regions.

Table 1. The RMSDs and MDs between CM SAF and DEEP-C, and TAL-AVHRR and DEEP-C during different seasons among different regions from 1985 to 2000.

\begin{tabular}{|c|c|c|c|c|c|}
\hline \multirow{2}{*}{ Area } & \multirow{2}{*}{ Season } & \multicolumn{2}{|c|}{ CM SAF } & \multicolumn{2}{|c|}{ TAL-AVHRR } \\
\hline & & RMSD & MD & RMSD & MD \\
\hline \multirow{4}{*}{$\begin{array}{c}90 \mathrm{~N}-90 \mathrm{~S}, \\
180 \mathrm{~W}-70 \mathrm{~W}\end{array}$} & MAM & & & 0.026 & 0 \\
\hline & JJA & & & 0.029 & -0.001 \\
\hline & SON & & & 0.027 & 0.007 \\
\hline & DJF & & & 0.024 & 0 \\
\hline
\end{tabular}


Table 1. Cont.

\begin{tabular}{|c|c|c|c|c|c|}
\hline \multirow{2}{*}{ Area } & \multirow{2}{*}{ Season } & \multicolumn{2}{|c|}{ CM SAF } & \multicolumn{2}{|c|}{ TAL-AVHRR } \\
\hline & & RMSD & MD & RMSD & MD \\
\hline \multirow{4}{*}{$\begin{array}{l}70 \mathrm{~N}-70 \mathrm{~S} \\
70 \mathrm{~W}-70 \mathrm{E}\end{array}$} & MAM & 0.029 & -0.004 & 0.019 & 0.001 \\
\hline & JJA & 0.016 & -0.002 & 0.022 & -0.003 \\
\hline & $\mathrm{SON}$ & 0.016 & 0.002 & 0.023 & 0.003 \\
\hline & DJF & 0.016 & 0.002 & 0.024 & 0 \\
\hline \multirow{4}{*}{$\begin{array}{l}90 \mathrm{~N}-90 \mathrm{~S}, \\
70 \mathrm{E}-180 \mathrm{E}\end{array}$} & MAM & & & 0.027 & 0.006 \\
\hline & JJA & & & 0.029 & 0 \\
\hline & $\mathrm{SON}$ & & & 0.031 & 0.011 \\
\hline & DJF & & & 0.028 & 0.008 \\
\hline
\end{tabular}

Table 2. RMSDs and MDs between CM SAF and CERES, TAL-AVHRR and CERES, and TAL-MODIS and CERES during different seasons among different regions from 2001 to 2015.

\begin{tabular}{|c|c|c|c|c|c|c|c|}
\hline \multirow{2}{*}{ Area } & \multirow{2}{*}{ Season } & \multicolumn{2}{|c|}{ CM SAF } & \multicolumn{2}{|c|}{ TAL-AVHRR } & \multicolumn{2}{|c|}{ TAL-MODIS } \\
\hline & & RMSD & MD & RMSD & MD & RMSD & MD \\
\hline \multirow{4}{*}{$\begin{array}{c}90 \mathrm{~N}-90 \mathrm{~S}, \\
180 \mathrm{~W}-70 \mathrm{~W}\end{array}$} & MAM & & & 0.016 & 0.016 & 0.015 & 0.004 \\
\hline & JJA & & & 0.017 & 0.017 & 0.016 & 0 \\
\hline & SON & & & 0.015 & 0.015 & 0.013 & 0 \\
\hline & DJF & & & 0.015 & 0.015 & 0.014 & 0.005 \\
\hline \multirow{4}{*}{$\begin{array}{l}70 \mathrm{~N}-70 \mathrm{~S} \\
70 \mathrm{~W}-70 \mathrm{E}\end{array}$} & MAM & 0.026 & -0.002 & 0.008 & 0 & 0.007 & -0.001 \\
\hline & JJA & 0.018 & 0.005 & 0.011 & 0 & 0.007 & -0.002 \\
\hline & SON & 0.016 & 0.006 & 0.012 & 0.001 & 0.012 & -0.002 \\
\hline & DJF & 0.015 & 0.003 & 0.014 & 0 & 0.013 & 0 \\
\hline \multirow{4}{*}{$\begin{array}{l}90 \mathrm{~N}-90 \mathrm{~S} \\
70 \mathrm{E}-180 \mathrm{E}\end{array}$} & MAM & & & 0.020 & 0.020 & 0.018 & 0.004 \\
\hline & JJA & & & 0.023 & 0.023 & 0.020 & 0 \\
\hline & $\mathrm{SON}$ & & & 0.021 & 0.021 & 0.019 & 0.006 \\
\hline & DJF & & & 0.022 & 0.022 & 0.018 & 0.008 \\
\hline
\end{tabular}

\section{Discussion}

In this study, there was good consistency among the five TOA albedo products after 2000. This is partly because DEEP-C uses CERES data after 2000, which was mentioned in Section 2.5. In addition, CERES data were also used when converting the instantaneous TAL-AVHRR and TAL-MODIS to the daily ones. However, considering that for these two datasets CERES data were only used to determine the conversion ratios, which are dependent on the observation time, the location, and the day of the year, it can be concluded that the good consistency between CERES, TAL-MODIS, and TAL-AVHRR shown in this study was not due to the usage of CERES data when generating the monthly TAL-MODIS and TAL-AVHRR, whose accuracy mostly depends on the accuracy of the retrieved instantaneous TOA albedo values.

These three products were used to calculate the trends of the TOA albedo in a $1^{\circ} \times 1^{\circ}$ grid based on the period 2001-2014 to show their differences in quantifying the variations at a global scale. The three products showed a similar pattern both in January and July, with an increase in the north of America, west of Europe, most parts of South America and Australia in January, and northeast of Asia in July, and a decrease in the east of Europe in January, and south of South America in July (Figure 10). TAL-AVHRR demonstrated a smaller trend magnitude than CERES and TAL-MODIS in the north 
of America and Australia in January, while in July, the three products showed quite similar patterns. The trends of the TOA albedo in the Antarctica were quite different in January, especially between TAL-MODIS and the other two, while in July, the trends of CERES in a small part of Greenland were the opposite to the other two. Specifically, CERES showed a decreasing trend $\left(-0.001\right.$ year $\left.^{-1}\right)$ in the west part of Greenland, while the other two showed an increasing trend $\left(0.001\right.$ year $\left.^{-1}\right)$. However, the trend was quite close in the east part of Greenland $\left(0.001\right.$ year $\left.^{-1}\right)$. Therefore, users should be careful when calculating the trend of the TOA albedo to prevent inconsistent conclusions, especially for high-latitude regions.
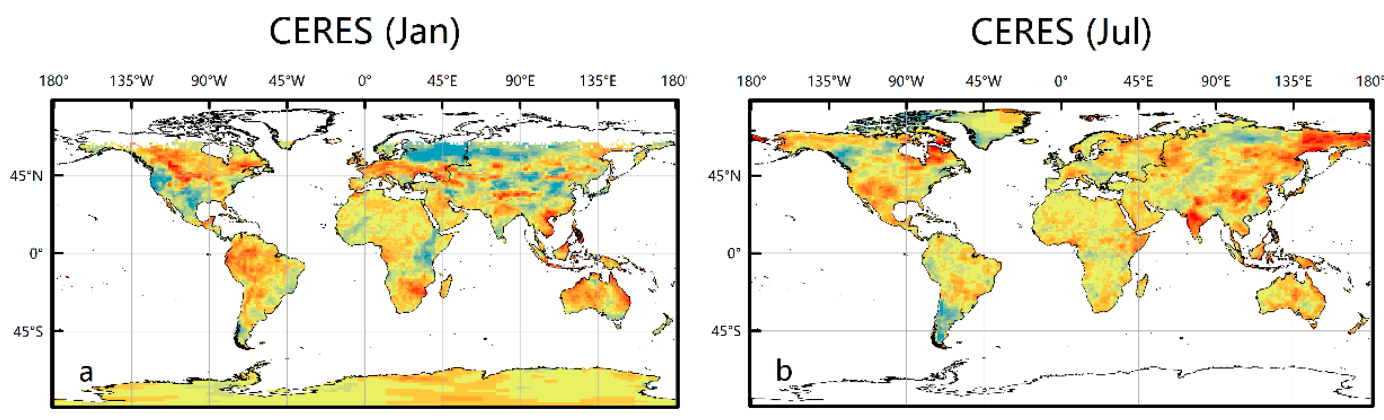

TAL-MODIS (Jan)

TAL-MODIS (Jul)
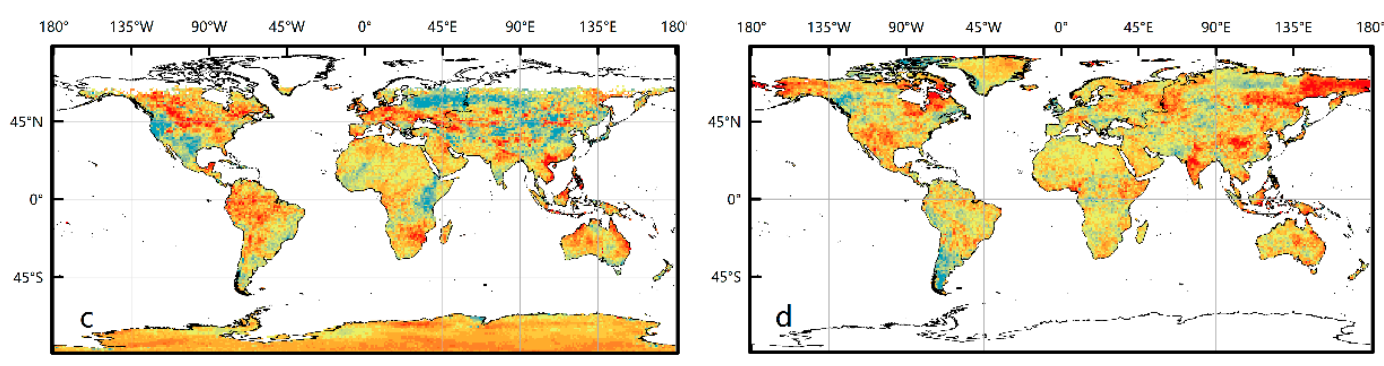

TAL-AVHRR (Jan)

TAL-AVHRR (Jul)
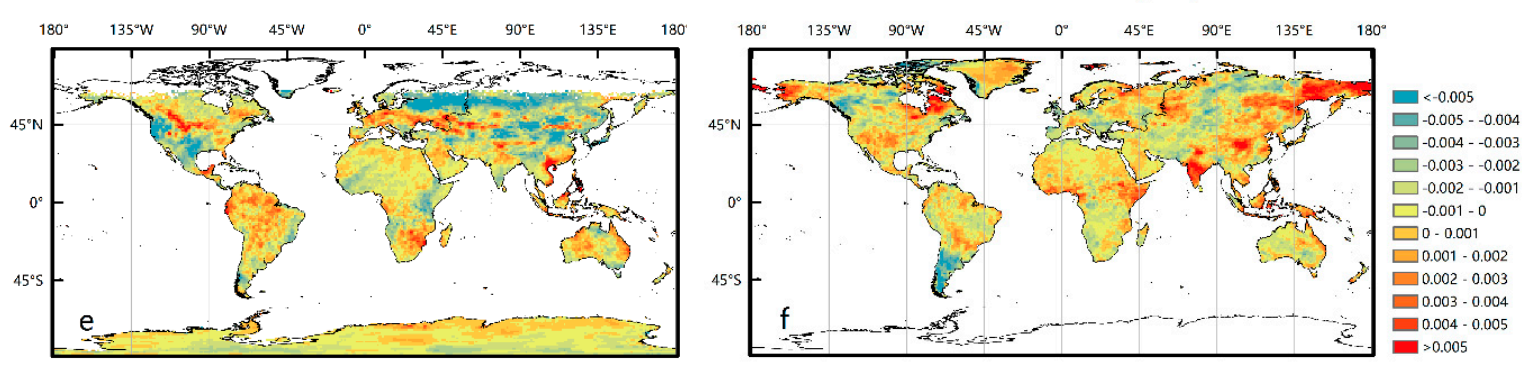

Figure 10. Trend of monthly mean TOA albedo in January from 2001 to 2014 based on (a) CERES; (c) TAL-MODIS; (e) TAL-AVHRR. (b,d,f) are the same but for July $\left(\right.$ year $\left.^{-1}\right)$.

\section{Conclusions}

We examined the differences in five TOA albedo datasets (i.e., TAL-AVHRR, TAL-MODIS, CERES, DEEP-C, and CM SAF) over land at different spatial scales in this study.

By comparing four products (i.e., TAL-AVHRR, TAL-MODIS, CERES, and DEEP-C) at global scale, of which DEEP-C uses CERES data from the year 2000 onwards, we found that the four products matched well with each other overall in mid-low latitude regions, where the percentage differences were less than $20 \%$. However, in some regions, particularly high-latitude regions, the differences were much larger. In addition to the problem of TAL-AVHRR during 1993 and 1994 caused by the unavailability of the source AVHRR data, TAL-AVHRR performed differently before and after 2000 . 
Regarding the trend of the TOA albedo, CERES, TAL-MODIS, and TAL-AVHRR performed similarly, but significant differences were found in the high-latitude regions, especially for Antarctica in January.

To demonstrate how these five TOA albedo products performed regionally, we divided the world area into ten parts, and calculated the corresponding deseasonalized anomalies and the absolute values of the TOA albedo. The results showed that the deseasonalized anomalies of the five products matched relatively well with each other. Before 2000, the differences among the three products (i.e., TAL-AVHRR, DEEP-C, and CM SAF) were much larger, particularly the differences between TAL-AVHRR and the other two products. The differences between the TAL-AVHRR and DEEP-C anomalies could approach 0.1 during some years before 2000, while the differences between DEEP-C and CM SAF in Europe and Africa were much smaller.

TOA albedo products were widely used in climate dynamic studies as TOA albedo is the key component of the Earth's energy budget. If the quality of the TOA albedo datasets is poor, inaccurate conclusions regarding the climatic system may be drawn, as a small underestimation or overestimation of the TOA albedo can lead to large errors when calculating the TOA shortwave upward flux. For the years before 2000, CM SAF is recommended for use in the mid-low latitude region of Africa and Europe, while DEEP-C is recommended in other regions. For the years after 2000, CERES and DEEP-C are recommended for use in the mid-low latitude regions while all five products are recommended for use in other regions.

Supplementary Materials: The following are available online at http://www.mdpi.com/2072-4292/11/24/2919/s1. Figure S1: Ten regions of the world; Figure S2: Monthly mean TOA albedo deseasonalized anomalies of different regions; Figure S3: Absolute value of monthly mean TOA albedo of different regions.

Author Contributions: S.L. and R.P.A. designed the experiment. D.W. and Z.S. collected and preprocessed the data. C.Z. and S.L. performed the experiment and conducted the analysis.

Funding: This research was partially funded by the National Key Research and Development Program of China (NO.2016YFA0600101) and the National Natural Science Foundation of China under Grant 41331173. Richard Allan was funded by the Natural Environment Research Council (NERC) SMURPHS Grant NE/N006054/1.

Acknowledgments: The CERES datasets can be downloaded at https://ceres-tool.larc.nasa.gov/ord-tool/jsp/ SYN1degEd4Selection.jsp. The first version of TAL-AVHRR was produced and updated in August 2017 and the datasets were released at http://www.geodata.cn/ and http://glcf.umd.edu/data. The TOA Radiation MVIRI/ SEVIRI Data Record has been implemented as part of the CM SAF of EUMETSAT and has been published under the DOI:10.5676/EUM_SAF_CM/TOA_MET/V001. The DEEP-C datasets can be downloaded at http://www.met.reading.ac.uk/ \{\}sgs02rpa/research/DEEP-C/GRL/. The POLDER-3/PARASOL BRDF database can be downloaded at URL: http://postel.mediasfrance.org/en/BIOGEOPHYSICAL-PRODUCTS/BRDF. We would like to thank the anonymous reviewers for their constructive comments and suggestions.

Conflicts of Interest: The authors declare no conflict of interest.

\section{References}

1. Trenberth, K.E.; Fasullo, J.T.; Kiehl, J. Earth's global energy budget. Bull. Am. Meteorol. Soc. 2009, 90, 311-324. [CrossRef]

2. Von Schuckmann, K.; Palmer, M.; Trenberth, K.; Cazenave, A.; Chambers, D.; Champollion, N.; Hansen, J.; Josey, S.; Loeb, N.; Mathieu, P.-P. An imperative to monitor Earth's energy imbalance. Nat. Clim. Chang. 2016, 6, 138. [CrossRef]

3. Barkstrom, B.R. The earth radiation budget experiment (ERBE). Bull. Am. Meteorol. Soc. 1984, 65, 1170-1185. [CrossRef]

4. Jacobowitz, H.; Soule, H.V.; Kyle, H.L.; House, F.B. The earth radiation budget (ERB) experiment: An overview. J. Geophys. Res. Atmos. 1984, 89, 5021-5038. [CrossRef]

5. Wielicki, B.A.; Barkstrom, B.R.; Harrison, E.F.; Lee, R.B.; Smith, G.L.; Cooper, J.E. Clouds and the Earth's Radiant Energy System (CERES): An earth observing system experiment. Bull. Am. Meteorol. Soc. 1996, 77, 853-868. [CrossRef]

6. Kandel, R.; Viollier, M.; Raberanto, P.; Duvel, J.P.; Pakhomov, L.; Golovko, V.; Trishchenko, A.; Mueller, J.; Raschke, E.; Stuhlmann, R. The ScaRaB earth radiation budget dataset. Bull. Am. Meteorol. Soc. 1998, 79, 765-784. [CrossRef] 
7. Duvel, J.-P.; Viollier, M.; Raberanto, P.; Kandel, R.; Haeffelin, M.; Pakhomov, L.; Golovko, V.; Mueller, J.; Stuhlmann, R.; Group, I.S.S.W. The ScaRaB-Resurs Earth radiation budget dataset and first results. Bull. Am. Meteorol. Soc. 2001, 82, 1397-1408. [CrossRef]

8. Loeb, N.G.; Manalo-Smith, N.; Loukachine, K.; Kato, S.; Wielicki, B. A new generation of angular distribution models for top-of-atmosphere radiative flux estimation from the Clouds and the Earth's Radiant Energy System (CERES) satellite instrument. In Proceedings of the 11th Conference on Atmospheric Radiation, Ogden, UT, USA, 4 June 2002.

9. Harries, J.E.; Russell, J.; Hanafin, J.; Brindley, H.; Futyan, J.; Rufus, J.; Kellock, S.; Matthews, G.; Wrigley, R.; Last, A. The geostationary earth radiation budget project. Bull. Am. Meteorol. Soc. 2005, 86, 945-960. [CrossRef]

10. Loeb, N.G.; Kato, S.; Loukachine, K.; Manalo-Smith, N. Angular distribution models for top-of-atmosphere radiative flux estimation from the Clouds and the Earth's Radiant Energy System instrument on the Terra Satellite. Part I: Methodology. J. Atmos. Ocean. Technol. 2005, 22, 338-351. [CrossRef]

11. Wang, X.; Key, J.R. Arctic surface, cloud, and radiation properties based on the AVHRR Polar Pathfinder dataset. Part I: Spatial and temporal characteristics. J. Clim. 2005, 18, 2558-2574. [CrossRef]

12. Wang, X.; Key, J.R. Arctic surface, cloud, and radiation properties based on the AVHRR Polar Pathfinder dataset. Part II: Recent trends. J. Clim. 2005, 18, 2575-2593. [CrossRef]

13. Roca, R.; Brogniez, H.; Chambon, P.; Chomette, O.; Cloché, S.; Gosset, M.E.; Mahfouf, J.-F.; Raberanto, P.; Viltard, N. The Megha-Tropiques mission: A review after three years in orbit. Front. Earth Sci. 2015, 3, 17. [CrossRef]

14. Loeb, N.G.; Doelling, D.R.; Wang, H.; Su, W.; Nguyen, C.; Corbett, J.G.; Liang, L.; Mitrescu, C.; Rose, F.G.; Kato, S. Clouds and the earth's radiant energy system (CERES) energy balanced and filled (EBAF) top-of-atmosphere (TOA) edition-4.0 data product. J. Clim. 2018, 31, 895-918. [CrossRef]

15. Wang, D.; Liang, S. Estimating high-resolution top of atmosphere albedo from Moderate Resolution Imaging Spectroradiometer data. Remote Sens. Environ. 2016, 178, 93-103. [CrossRef]

16. Urbain, M.; Clerbaux, N.; Ipe, A.; Tornow, F.; Hollmann, R.; Baudrez, E.; Velazquez Blazquez, A.; Moreels, J. The CM SAF TOA radiation data record using MVIRI and SEVIRI. Remote Sens. 2017, 9, 466. [CrossRef]

17. Song, Z.; Liang, S.; Wang, D.; Zhou, Y.; Jia, A. Long-term record of top-of-atmosphere albedo over land generated from AVHRR data. Remote Sens. Environ. 2018, 211, 71-88. [CrossRef]

18. Nakamura, N.; Oort, A.H. Atmospheric heat budgets of the Polar Regions. J. Geophys. Res. Atmos. 1988, 93, 9510-9524. [CrossRef]

19. Trenberth, K.E.; Stepaniak, D.P. Covariability of components of poleward atmospheric energy transports on seasonal and interannual timescales. J. Clim. 2003, 16, 3691-3705. [CrossRef]

20. Trenberth, K.E.; Stepaniak, D.P. Seamless poleward atmospheric energy transports and implications for the Hadley circulation. J. Clim. 2003, 16, 3706-3722. [CrossRef]

21. Fasullo, J.T.; Trenberth, K.E. The annual cycle of the energy budget. Part II: Meridional structures and poleward transports. J. Clim. 2008, 21, 2313-2325. [CrossRef]

22. Fasullo, J.T.; Trenberth, K.E. The annual cycle of the energy budget. Part I: Global mean and land-ocean exchanges. J. Clim. 2008, 21, 2297-2312. [CrossRef]

23. Cullather, R.I.; Bosilovich, M.G. The energy budget of the polar atmosphere in MERRA. J. Clim. 2012, 25, 5-24. [CrossRef]

24. Smith, D.M.; Allan, R.P.; Coward, A.C.; Eade, R.; Hyder, P.; Liu, C.; Loeb, N.G.; Palmer, M.D.; Roberts, C.D.; Scaife, A.A. Earth's energy imbalance since 1960 in observations and CMIP5 models. Geophys. Res. Lett. 2015, 42, 1205-1213. [CrossRef] [PubMed]

25. Trenberth, K.E.; Fasullo, J.T. Atlantic meridional heat transports computed from balancing Earth's energy locally. Geophys. Res. Lett. 2017, 44, 1919-1927. [CrossRef]

26. Mayer, M.; Alonso Balmaseda, M.; Haimberger, L. Unprecedented 2015/2016 Indo-Pacific Heat Transfer Speeds Up Tropical Pacific Heat Recharge. Geophys. Res. Lett. 2018, 45, 3274-3284. [CrossRef]

27. Zhan, Y.; Di Girolamo, L.; Davies, R.; Moroney, C. Instantaneous Top-of-Atmosphere Albedo Comparison between CERES and MISR over the Arctic. Remote Sens. 2018, 10, 1882. [CrossRef]

28. Wielicki, B.A.; Barkstrom, B.R.; Baum, B.A.; Charlock, T.P.; Green, R.N.; Kratz, D.P.; Lee, R.B.; Minnis, P.; Smith, G.L.; Wong, T. Clouds and the Earth's Radiant Energy System (CERES): Algorithm overview. IEEE Trans. Geosci. Remote Sens. 1998, 36, 1127-1141. [CrossRef] 
29. Doelling, D.R.; Loeb, N.G.; Keyes, D.F.; Nordeen, M.L.; Morstad, D.; Nguyen, C.; Wielicki, B.A.; Young, D.F.; Sun, M. Geostationary enhanced temporal interpolation for CERES flux products. J. Atmos. Ocean. Technol. 2013, 30, 1072-1090. [CrossRef]

30. Allan, R.P.; Liu, C.; Loeb, N.G.; Palmer, M.D.; Roberts, M.; Smith, D.; Vidale, P.L. Changes in global net radiative imbalance 1985-2012. Geophys. Res. Lett. 2014, 41, 5588-5597. [CrossRef]

31. Rao, Y.; Liang, S.; Yu, Y. Land surface air temperature data are considerably different among BEST-LAND, CRU-TEM4v, NASA-GISS, and NOAA-NCEI. J. Geophys. Res. Atmos. 2018, 123, 5881-5900. [CrossRef]

32. Trenberth, K.E.; Zhang, Y. How often does it really rain? Bull. Am. Meteorol. Soc. 2018, 99, 289-298. [CrossRef]

(C) 2019 by the authors. Licensee MDPI, Basel, Switzerland. This article is an open access article distributed under the terms and conditions of the Creative Commons Attribution (CC BY) license (http://creativecommons.org/licenses/by/4.0/). 